\title{
VIOLÊNCIAS NA ESCOLA: DIFERENTES ATORES E INTERPRETAÇÕES
}

\author{
Ângela $\mathrm{M}^{\mathrm{a}} \mathrm{P}$. da SILVA ${ }^{1}$ \\ Gehysa Alves GUIMARÃES ${ }^{2}$ \\ Eliete Ribeiro FALCÃO ${ }^{3}$ \\ Doris Cristina GEDRAT ${ }^{4}$ \\ Myriam de MELO ${ }^{5}$ \\ Nathalia WEIGEL ${ }^{6}$ \\ Natállia Boff OLIVEIRA ${ }^{7}$ \\ Deborah Luíza Christ LONDERO ${ }^{8}$ \\ Luisa Soares RUSSO ${ }^{9}$ \\ Johana GRIGIO ${ }^{10}$
}

\section{INTRODUÇÃO}

Este estudo ${ }^{11}$ surge do interesse em aprofundar o conhecimento sobre as violências no contexto escolar e de que forma essas práticas são percebidas ou não pelos diferentes sujeitos (alunos, professores e corpo diretivo). Embora o Brasil tenha avançado nos marcos legais, com a Declaração Universal de Direitos Humanos,o Estatuto da Criança e do Adolescente, Estatuto da Juventude, a Lei Maria da Penha, o Estatuto da Igualdade Racial,dentre outros, no campo de respostas estatais ao problema, ainda há carência de ações concretas e efetivas para a coibição da violência, em especial, no contexto educacional.

${ }^{1}$ Universidade Luterana do Brasil (ULBRA) Canoas, Brasil.

${ }^{2}$ Universidade Luterana do Brasil (ULBRA) Canoas, Brasil.

${ }^{3}$ Universidade Luterana do Brasil (ULBRA) Canoas, Brasil.

${ }^{4}$ Universidade Luterana do Brasil (ULBRA) Canoas, Brasil.

${ }^{5}$ Universidade Luterana do Brasil (ULBRA) Canoas, Brasil.

${ }^{6}$ Universidade Luterana do Brasil (ULBRA) Canoas, Brasil.

${ }^{7}$ Universidade Luterana do Brasil (ULBRA) Canoas, Brasil.

${ }^{8}$ Universidade Luterana do Brasil (ULBRA) Canoas, Brasil.

${ }^{9}$ Universidade Luterana do Brasil (ULBRA) Canoas, Brasil.

${ }^{10}$ Universidade Luterana do Brasil (ULBRA) Canoas, Brasil.

${ }^{11}$ O projeto de pesquisa surgiu de uma iniciativa do Curso de Serviço Social da ULBRA/ Canoas, do qual faço parte, que desde 2012 desenvolve projetos de extensão comunitária nessa temática com jovens alunos de Ensino Médio. Em decorrência dessa complexidade foi constituído o referido projeto contemplando a participação docente de Ângela Ma Pereira da Silva, Ana Patrícia Barbosa, Caroline Fernanda Santos da Silva, Gehysa Guimarães Alves, Eliete Ribeiro Falcão, Doris Cristina Gedrat e André Guirland Vieira como docentes voluntários. Assim como aparticipação de discentes do Curso de Medicina com contribuição das acadêmicas Luisa Russo Soares, Johana Grigio, Natállia Boff de Oliveira, Deborah Luíza Christ Londero, Nathalia Weigel e Myriam de Melo, na condição de voluntárias do projeto.

Iluminuras, Porto Alegre, v. 19, n. 47, p. 210-226, dec, 2018. 
Deste modo, a escola é um espaço que deveria promover atividades voltadas ao pleno desenvolvimento de crianças, adolescentes e jovens, contribuindo com a criação de espaços de reflexão sobre a importância de fortalecer estilos de vida mais saudáveis à comunidade escolar. O processo de participação democrática no ambiente escolar favorece a formação cidadã, além do desenvolvimento de habilidades e atitudes necessárias a vivência social e para o mundo do trabalho. Nessa perspectiva, a democracia e os processos participativos aparecem como valor, pressuposto e caminhos indispensáveis (Demo, 1988).

Neste sentido, a escola pode contribuir como um espaço de boas práticas de saúde, promovendo a educação integral, e garantindo ambientes protetivos, de forma a que todos os sujeitos implicados nesse processo possam se comprometer com a promoção da paz e da justiça social. Diante do exposto, os temas transversais relacionados às violências, gênero, corpo, sexualidade, diversidades, desigualdade e inclusão social devem ser considerados no currículo escolar. Neste processo, a escola que promove a saúde deve priorizar relações de respeito e tolerância entre os diferentes grupos, prevendo a participação ${ }^{12}$ dos atores na seleção dos temas a serem debatidos em sala de aula. Outro elemento importante a ser considerado é a análise sobre as relações sociais que se estabelecem no ambiente escolar, se estão postas como protetivas ou impeditivas ao convívio social.

A sala de aula é um espaço que deve propiciar a reflexão de conteúdos articulados à realidade social e cultural à qual estão inseridos alunos, professores e corpo diretivo, tendo como uma das estratégias metodológicas o diálogo, a resolução de conflitos, de relações verticais de poder e a reflexão crítica do cotidiano. Isso favorece o comprometimento da comunidade escolar com a manutenção de um espaço protetivo e participativo para todos. A escola é um espaço de vivência entre esses sujeitos que convivem com a situação de

12 Estatuto da Juventude (Lei n. ${ }^{\circ}$ 12.852, de 5 de agosto de 2013.) artigo $4^{\circ}$, a saber: O jovem tem direito à participação social e política e na formulação, execução e avaliação das políticas públicas de juventude. Parágrafo único. Entende-se por participação juvenil: I - a inclusão do jovem nos espaços públicos e comunitários a partir da sua concepção como pessoa ativa, livre, responsável e digna de ocupar uma posição central nos processos políticos e sociais; II - o envolvimento ativo dos jovens em ações de políticas públicas que tenham por objetivo o próprio benefício, o de suas comunidades, cidades e regiões e o do País; III - a participação individual e coletiva do jovem em ações que contemplem a defesa dos direitos da juventude ou de temas afetos aos jovens; e IV - a efetiva inclusão dos jovens nos espaços públicos de decisão com direito a voz e voto.

Iluminuras, Porto Alegre, v. 19, n. 47, p. 210-226, dec, 2018. 
desigualdade de poder, com as diferenças e iniquidades existentes entre os diferentes grupos sociais. Ela tornou-se ponto do encontro, de convivência social, e palco potencial à fecundação da cidadania (Amaro, 2012). Em função disso, é fundamental que oportunize que a sala de aula propicie a reflexão sobre as várias interpretações sobre a realidade social e cultural, por vezes atravessada pelas manifestações das violências no contexto escolar a partir de uma discussão sobre os princípios éticos e sobre as questões que interferem direta ou indiretamente na vida de cada um/a, respeitando os diversos entendimentos sobre os modos de ser e de viver e, consequentemente, possibilitando às pessoas uma vivência mais saudável na sociedade contemporânea. O protagonismo dos sujeitos é uma forma de pensar que concebe a pessoa como fonte de iniciativa, que é ação e como fonte de liberdade, ou seja, que tem a escolha, o compromisso e a responsabilidade(Rui Mesquita on-line ${ }^{13}$ ).No caso da escola, o contrário disso pode incidir na evasão escolar dos alunos, no adoecimento dos professores e até mesmo no constante remanejo dos mesmos na rede escolar.

A deteriorização das relações pessoais tem inviabilizado o processo de ensinar e aprender o que tem suscitado o desencanto pela docência, desrespeito entre alunos e professores, desinteresse e o julgamento de que nada mais vale a pena, mesmo para os mais jovens (Abramovay, 2006). A instituição escolar sempre produziu desigualdades de poder, até mesmo fazendo a distinção entre os sujeitos que frequentavam a escola dos que não tinham acesso, demarcando distinções entre adultos e crianças, ricos e pobres e meninos e meninas. Desse modo, a escola ensina o que pode ser desejado ou não e os gestos e os movimentos que o território escolar produz são sentidos e incorporados pelos alunos, professores e corpo diretivo (Louro, 1999).

No transcorrer do presente estudo fomos surpreendidas pela aprovação do Novo Plano Nacional de Educação (PNE), que excluiu os termos “identidade de gênero” e “diversidade sexual” do currículo escolar, por pressão de movimentos conservadores que concebem que essa discussão compete à família e não à escola. O movimento assumido como Escola Sem Partido ${ }^{14}$ surge como uma resistência a possíveis transformações sociais

\footnotetext{
${ }^{13}$ Fonte disponível: https://ruimesquita.wordpress.com/2003/04/17/do-protagonismo-ao-empreendedorismosocial/

14
} 
que venham a empoderar grupos historicamente assujeitados e a promover a inclusão dos excluídos (Saraiva e Vargas, 2017).

Assim, atendendo à demanda de setores conservadores do Congresso Nacional, o Ministério da Educação (MEC) retirou termos como “identidade de gênero" e "orientação sexual” da Base Nacional Comum Curricular $\left(\mathrm{BNCC}^{15}\right)$. Logo, o movimento de setores conservadores em alguns municípios do Brasil, tomando, por exemplo, São Paulo, com seu Plano Municipal de Educação, desde o ano de 2015, fez a remoção de todos os trechos em que a palavra "gênero" era citada no referido Plano $\left(\right.$ on-line $\left.e^{16}\right)$. Na medida em que o fenômeno da violência é cultural, eclético e democrático, ou seja, atinge todos os sujeitos e grupos, independente da classe social, faixa etária, raça-etnia, gênero, nacionalidade e outras intersecções, há a necessidade de análises mais aprofundadas dessa questão, suas manifestações e condicionamentos culturais.Além disso, a violência, seja de gênero, de classe social ou de raça, são temas que precisam ser discutidos no cotidiano escolar, sob pena de escamotear a realidade existente dentro dos espaços da educação formal.

Promover um diálogo acerca desses temas é fundamental. Este estudo auxilia professores e alunos a pensarem sobre eles e instiga a refletir sobre como as diversas formas de violência tem se apresentado na instituição escolar, sendo este o objetivo deste estudo. Assim, falar sobre violências na escola implica em promover a saúde da comunidade escolar e a reflexão de alunos, professores, corpo diretivo na escola, pois não falar/pensar sobre esses temas desvela a violação dos direitos dos sujeitos implicados, que por vezes são relativizadas ou até mesmo naturalizadas, seja pela exposição ou participação.

PLS 193/2016 projeto que pretende alterar a Lei de Diretrizes e Bases da Educação. Visa eliminar a discussão ideológica no ambiente escolar, restringir os conteúdos de ensino a partir de um pressuposto de neutralidade por parte dos educadores.

15

A versão de abril/2016 da BNCC foi entregue para análise ao Conselho Nacional de Educação (CNE) e aguarda a aprovação do mesmo. Caso aprovada, as escolas deverão se adaptar às novas normas a partir de 2019.

16

Fonte: http://pensaraeducacao.com.br/pensaraeducacaoempauta/a-retirada-do-termo-genero-dosplanos-estaduais-e-municipais-de-educacao-algumas-questoes-a-pensar-exclusivo/

Iluminuras, Porto Alegre, v. 19, n. 47, p. 210-226, dec, 2018. 


\section{MÉTODO}

Trata-se de um estudo exploratório, descritivo de série de casos, com abordagem qualitativa.Conforme Leopardi (Leopardi, 2001), a pesquisa exploratória é um levantamento das características conhecidas de fatos, fenômenos ou problemas de determinada realidade social e cultural, e assim descrevendo essas informações sobre o que se deseja estudar. Este tipo de pesquisa tem por finalidade demonstrar fatos ou características da população e da comunidade como objetivo primordial de proporcionar visão geral, de tipo aproximativo, sobre determinado fato (Gil, 2002). Sendo assim, a escolha pela pesquisa qualitativa ocorre pelo fato desta contemplar um nível de realidade a partir de seus significados, valores, crenças, que expressam a realidade dinâmica entre o mundo real e a subjetividade dos sujeitos.

A coleta dos dados ocorreu a partir de questionário autoaplicado nas dependências das duas escolas em horário de melhor conveniência para todos e acordado previamente com a Direção de cada escola. A coleta de dados ocorreu entre novembro de 2017 e maio de 2018. Valemo-nostambém da observação não participante e do diário de campo em ambas as escolas estaduais de um município da Região Metropolitana de Porto Alegre/RS.

Os dados obtidos foram analisados de forma qualitativa e interpretados conforme a técnica de análise de conteúdo com base em Bardin (Bardin, 2009), que a concebe como um conjunto de técnicas de comunicação que visa obter, por procedimentos sistemáticos e objetivos de descrição de conteúdos das mensagens, indicadores (quantitativos ou não) que permeiam a interferência de conhecimentos relativos às condições de produção/recepção destas mensagens.

A observação não participante ocorre na medida em que o pesquisador está em contato com o grupo pesquisado, mas não se envolve nas situações observadas (Marconi, Lakatos, 2011: 78). O diário de campo consiste no registro das observações em sala de aula, nas dependências da escola e seu entorno, bem como dos relatos pontuais da interface com os participantes e da realidade social e cultural. O desenvolvimento deste estudo respeitou todos os preceitos éticos que envolvem pesquisa com seres humanos estabelecidos pela Resolução nº 466, do ano de 2012 do Ministério da Saúde (Brasil, 2012a). Inclusive a

Iluminuras, Porto Alegre, v. 19, n. 47, p. 210-226, dec, 2018. 
identificação dos sujeitos participantes foi acordada na coleta de dados, utilizando-se nomes de flores para respeitar o anonimato e a identidade dos mesmos.

O estudo obteve autorização das escolas e parecer favorável do Comitê de Ética em Pesquisa da ULBRA, sob o número 2.175.398, em julho de 2017.

\section{RESULTADOS E DISCUSSÃO}

\section{O ambiente escolar}

Nas visitas nas duas escolas investigadas, observamos murais expostos nos corredores e áreas comuns com várias informações a respeito de projetos sociais que contemplam o público escolar e o cronograma de atividades extracurriculares aos alunos por meio de parcerias intergovernamentais. Parte dessas atividades ocorre através do estabelecimento de um vínculo entre as universidades e essas escolas, envolvendo pesquisadores, professores e acadêmicos dessas instituições e de diferentes áreas do conhecimento engajados em objetivos comuns. Os materiais informativos dessas ações ficam expostos para que a comunidade escolar possa ser esclarecida e orientada sobre os eventos que ocorrem dentro da escola e em seu entorno.

Os resultados desse estudo mostraram regular estado de conservação das duas escolas no que diz respeito à higiene, às dependências da escola, às salas de aula, corredores e banheiros. Entretanto, é importante que possam ser investidos recursos para as escolas para que elas possam investir na ampliação e reforma dos seus prédios, construídos na década de 1970,pois um ambiente renovado é um dos elementos fundamentais para a educação de qualidade.

Outro fator evidenciado nesta pesquisa diz respeito à sala de multimeios, à biblioteca e ao laboratório de informática, que são extensões da sala de aula. Em ambas as escolas há a necessidade de recursos pedagógicos e tecnológicos, falta bibliotecário/a e recursos orçamentários para aplicar nessas questões.O corte de financiamento da política de educação têm, consequentemente, impacto no ambiente escolar, na precarização do ensino,

Iluminuras, Porto Alegre, v. 19, n. 47, p. 210-226, dec, 2018. 
no processo de trabalho dos professores, entre outros fatores.

Ainda destaca-se no espaço escolar a presença de portões e grades de ferro em suas instalações, até nos reportando ao sistema carcerário. Para Foucault (1987), visando a atingir o ideal de “ortopedia social”, em que a permanente vigilância representa tática de eficácia, a escola é um dos espaços sociais apropriados para produzir o “corpo dócil”, economicamente produtivo, socialmente civilizado, politicamente disciplinado e culturalmente devotado à prática e às razões do Estado.

Além disso, as duas escolas investigadas tomam precauções com relação ao controle no acesso às suas dependências através de circuito de câmeras de segurança, que aparentemente se encontravam em funcionamento no momento das visitas. Também adotam a apresentação de um cartão de identificação para o controle do acesso e a liberação de entrada/ saída nas dependências da escola. Isso é percebido pelos participantes desse estudo como medidas preventivas necessárias para garantir a segurança de alunos, professores e corpo diretivo. Nesse sentido, o controle de acesso nas escolas é tido como um aspecto que favorece um ambiente protetivo, inibindo possíveis situações de violência, assalto ou sequestro.

Sob outro ângulo, a escola atendendo à lógica do mercado, na perspectiva de Foucault, nestas instituições, propositadamente, o corpo é visto como um objeto, capaz de ser domesticado, “adestrado” a partir de normas e punições, para que assim todos exerçam suas tarefas como bons cidadãos evitando infringir as normas estabelecidas pelo poder. É possível correlacionar à percepção dos professores e alunos com relação à segurança no ambiente escolar em razão da sua localização de fácil acesso, o que favorece a concentração de um número expressivo de alunos pela oferta de transporte público e pela proximidade com um posto policial que faz o patrulhamento no entorno, em especial, nos horários de entrada e saída.

Uma das escolas, além do ensino médio, ofertado no turno da noite, também há um curso profissionalizante que atrai um público que quer se (re)inserir no mundo do trabalho. Feitas tais considerações, vale pontuar que a percepção do corpo diretivo das duas escolas investigadas sobre a figura do professor é de que este está sempre cansado e preocupado com a sua carreira profissional, se sentem desvalorizados, não somente pelo Governo do 
Estado, mas também pelos gestores locais, já que não são motivados ao trabalho e nem são oportunizados espaços de reflexão sobre o trabalho e formas de melhorá-lo a nível local. Nas questões relativas aos serviços prestados na escola pela Secretaria, Direção e Orientação Educacional, esses atendem às necessidades de professores e alunos e foram classificados entre bom e ótimo. Também foi observado que entre alunos e professores a relação é de tolerância e isso foi evidenciado nas interações no pátio, nos espaços esportivos e na saída da sala de aula, o que eminentemente contribui para o cumprimento das aulas.

Contudo, tolerância não significa respeito à diversidade e entendimento da complexidade das relações vivenciadas em sala de aula. Essa percepção, aliada as ações e atividades extracurriculares mencionadas anteriormente envolvendo os diferentes atores sociais (alunos, professores, direção, acadêmicos, pesquisadores) pode incidir positivamente no contexto escolar, contribuindo para que alunos e professores possam reconhecer e denunciar as variadas formas de violência.

\section{Percepções dos professores em relação às violências na escola}

Em relação aos 14 professores entrevistados, esses demonstraram falta de conhecimento sobre os diferentes tipos de violência, além de uma resistência inicial ao preenchimento do questionário. Segundo Minayo, "[...] é muito difícil conceituar a violência, principalmente por ser ela, por vezes, uma forma própria de relação pessoal, política, social e cultural; por vezes uma resultante das interações sociais; por vezes, ainda, um componente cultural naturalizado" (Minayo, 1999: 10). No momento do preenchimento do questionário, alguns professores mencionaram que xingamentos e agressões verbais são situações corriqueiras na escola e, na maioria das vezes, é aceita ou relativizada pelos diferentes sujeitos e grupos que ali transitam.

De modo geral, os professores, inicialmente,ficaram reticentes sobre o preenchimento do questionário, questionando se os resultados deste estudo poderiam contribuir para promover 
melhorias no ambiente escolar e o desempenho das suas atividades. Essa descrença sobre as possibilidades da pesquisa e da reflexão sobre esses temas pode estar correlacionada à sobrecarga de atribuições assumidas pelo professor na atualidade, que extrapola dos currículos escolares para outras tarefas administrativas: controle no acesso às dependências da escola, suporte na biblioteca, na sala de multimeios e no laboratório de informática. A instituição escolar é vista, portanto, como aquela que maltrata os alunos, professores, famílias pela sua omissão, autoritarismo e negligência. Esta é uma forma de violência, chamada violência institucional, e muitas vezes negada e invisível para as escolas (Paim, 2002).A violência no cotidiano escolar envolve três dimensões socioorganizacionais distintas: degradação no ambiente escolar, resultando em estruturas deficientes; violência que se origina de fora para dentro das escolas, desde gangues, tráfico de drogas e exclusão social na comunidade escolar. Isso foi perceptível nas duas escolas visitadas (Debarbieux, 1999).

Feitas essas considerações, vale mencionar que em novembro de 2017, por ocasião da coleta de dados, os professores retornavam de um longo período de paralisação e mantinham somente $60 \%$ das atividades da escola em funcionamento. Com isso,sentiam-se sobrecarregados para dar conta das várias atribuições que tinham que desempenhar para além do espaço da sala de aula. Inclusive, isso dificultou a participação de todos os professores que se encontravam na referida escola no processo da pesquisa, pois alguns precisavam organizar a divisão das tarefas e as executar as combinações estabelecidas com os alunos e com o corpo diretivo.

O longo período de paralisação culminou na supressão de debates mais abrangentes sobre temas transversais que deveriam ocorrer em sala de aula, pois os conteúdos primordiais foram priorizados em detrimento das temáticas sociais. A confrontação dos desejos com as realidades e as possibilidades de compreender e transformar o mundo que nos rodeia parecem distanciar-se cada vez mais do espaço da educação, pois conteúdos técnicos são geralmente priorizados em detrimento da formação da subjetividade e das reflexões sobre o cotidiano e das questões que afetam as maneiras de viver (Varela, 1999). Em relação aos professores da segunda escola investigada,sua percepção sobre os motivos de tensionamento com os alunos giravam em torno dos momentos de avaliações, do número 
elevado de alunos por turma, da falta de conscientização dos alunos e das discussões e vivências sobre as questões de violência e suas repercussões. Além disso, os mesmos referiram pouco incentivo dos governantes com a política de educação, o que, para eles,prejudica o dia a dia na escola, a qualidade de ensino e a inclusão das temáticas transversais no currículo escolar.

Os professores relataram dificuldades em trabalhar com temas transversais nas duas escolas investigadas. Atribuíram essa limitação à falta de capacitação para lidar com esses temas em sala de aula e no cotidiano escolar. A educação continuada é uma necessidade. No entanto, nem sempre os docentes aceitam esses momentos, pois ela por si só pode não resolver de forma definitiva as questões de formação profissional (Fabris, 2011). Além da educação permanente, os professores demonstraram que suas principais preocupações giram em torno das atuais dificuldades implicadas no trabalho na Rede Estadual de Ensino, desde a desvalorização do professor, os atrasos regulares de salários, a falta de reajustes salariais e ausência de educação continuada, além da falta de espaço de reuniões periódicas dentro da escola em função do excesso de trabalho e, consequentemente, o adoecimento no trabalho. Essas dificuldades têm sido enfrentadas pelos professores esão apontadas em outro estudo, haja vista a baixa remuneração e más condições de trabalho somam-se a censura permanente (Saraiva e Vargas, 2017). Ao serem questionados sobre como a escola lida com situações de violências no cotidiano,os professores referem a sensação de impotência frente às ofensas e gestos obscenos, nesses momentos conflitivos a ideia de pedir remanejo, da sensação de desvalorização profissional, das tratativas a cada episódio de violência na busca de uma postura empática por parte dos perpetuadores.Sentimentos de preocupação, impotência, desmotivação, medo e insegurança são algumas das referências causais dessa violência vivida e percebida por parte de professores e monitores no ambiente escolar (Abramovay, 2016).

Observa-se que os professores referem os alunos como sendo pessoas desinteressadas pelos conteúdos, por vezes, desrespeitosos e percebidos como causadores de problemas disciplinares. As violências na escola têm identidade própria, ainda que se expressem 
mediante formas comuns, como incivilidades, preconceitos, desconsiderações aos outros e às diversidades (Abramovay e Rua, 2002).

Assim, a fala dos professores acaba reforçando outra forma de violência, exercida pelo professor de forma a culpabilizar o aluno pelo seu desinteresse em sala de aula. Em momento nenhum questionam sua atuação, a metodologia utilizada e a articulação do conteúdo teórico com a vida cotidiana. Deste modo, salienta-se a importância da intensificação do debate sobre esses temas pouco explorados nesse espaço em decorrência desses vários limitadores. Com isso, tristemente a multiplicidade nas formas de existir e de pensar é calada a todo o momento, tendo como exemplo a necessidade de se refletir sobre as formas de violência e as suas manifestações, dentro do ambiente escolar.

\section{Perspectivas dos alunos em relação às violências na escola}

Com relação aos alunos,nas duas escolas, esses não percebem o espaço escolar atuando para diminuir as situações estressoras, conflitivas e de violência, pois afirmam que boa parte dos professores faz de conta que não viram situações de violência e relevam outras para não se incomodarem e não criarem mais tensionamentos em sala de aula. Também referem perceber que os professores estão sobrecarregados com o excesso de atividades para as quais são solicitados. Quando questionados sobre suas sugestões para melhorar a violência na sua escola, a maioria dos alunos mencionou: diálogo, respeito, a empatia, ouvir os dois lados da história, dar solução ao ocorrido e buscar o melhor entendimento entre as partes envolvidas. Também pontuaram a necessidade de professores terem mais iniciativa e atitude, da mesma forma que referiram a necessidade da direção da escola ter mais seriedade na apuração das situações conflitivas.

Com relação à violência entre alunos, a aluna Margarida ${ }^{17}$ afirma que "Já presenciei diversas vezes a violência física, moral e psicológica. Em relação à violência física, os alunos levaram advertência, mas nada ocorre”. No que diz respeito à inter-relação professores e alunos a mesma apontou que "Já também, diversas vezes, professores

17

Neste estudo será utilizada a nomenclatura de flores, assim sendo devidamente respeitado o anonimato dos participantes.

Iluminuras, Porto Alegre, v. 19, n. 47, p. 210-226, dec, 2018. 
humilhando alunos e vice-versa. Quando a violência moral ocorreu da parte dos professores, eles saíram ilesos e os alunos sequer foram escutados. Quanto foi da parte do aluno, os pais foram acionados”.

Essa narrativa poderia ser pensada a partir da concepção de Caciano e Silva (Caciano e Silva, 2012), se a relação aluno/professor fosse vista como uma relação de aprendizagem, que engloba amizade, criação, afeto, saber e aprender, não faria com que o poder do professor fosse destruído, acabado, mas haveria o respeito, o desejo de aprender e trocar experiências. A forma como utilizamos o poder é que precisa ser repensada. Nas situações conflitivas, quando os professores não conseguem intervir, os alunos são encaminhados para o Serviço de Orientação Educacional da escola. Nesse espaço há uma conversa com eles e, dependendo da situação, recebem uma punição ou devem voltar somente acompanhados dos pais. Isso, não raro, acaba por gerar maior estresse nas relações envolvendo alunos, professores e as famílias. Para os alunos, essas medidas dificultam o diálogo, o respeito e a empatia entre os envolvidos, bem como dispensam a direção de ouvir os dois lados da história.

De outro lado, os alunos percebem que os professores não se sentem responsabilizados pelo seu fracasso escolar, que atribuem a culpa a eles, desconsideram as suas precárias condições de vida e não oferecem a reflexão sobre os assuntos que aparecem em seu cotidiano de vida. Refletir sobre a violência na escola e fora dela é um tema que, atualmente, a escola não pode mais se eximir, pois além de estar incluído nas bases das Diretrizes Nacionais da Educação, é uma vivência cada vez mais forte e assustadora dentro do ambiente escolar.

Abramovay (Abramovay, 2002) aponta que tanto os jovens como outros membros do contexto escolar relatam que a violência deixou de ser um componente de excepcionalidade e se disseminou a tal ponto que se naturalizou, se banalizou, passando a ser elemento comum no cotidiano. Nesse sentido, não há mais como negar o problema, pois negá-lo é contribuir para seu agravamento.

Deste modo, a discussão sobre a violência deve estar em pauta constante no âmbito educacional, pois há a necessidade de fomentar pesquisas e planejar ações a fim de

Iluminuras, Porto Alegre, v. 19, n. 47, p. 210-226, dec, 2018. 
minimizá-la. A violência vivenciada tanto na vida dos alunos quanto dos professores tem impacto importante nas relações e na permanência ou não dessas pessoas dentro da escola. Deste modo, tal discussão poderá auxiliar a visualizar coletivamente um conjunto de comportamentos, atitudes, expectativas, valores e estereótipos associados aos indivíduos no âmbito escolar.

Os resultados deste estudo apontam possíveis obstáculos para a aplicabilidade de uma política efetiva na prevenção às violências, na medida em que a escola é atravessada por uma série de demandas fruto das transformações societárias que extrapolam os currículos.O alargamento das funções da escola reconfigura as atividades com que os professores têm que se envolver em seu cotidiano, acabando por sobrar poucos espaços para a reflexão sobre esses temas, fundamentais para qualificar o espaço escolar e melhorar a vida de toda a comunidade escolar. Nas palavras de Young:

$$
\begin{aligned}
& \text { [...] as propostas têm negligenciado, ou pelo menos minimizado, o papel } \\
& \text { educacional fundamental do currículo, que decorre tanto daquilo para que as } \\
& \text { escolas servem quanto do que elas podem ou não podem fazer. Ao mesmo tempo } \\
& \text { em que devemos permanecer atentos ao contexto mais amplo, as escolhas } \\
& \text { curriculares devem ser tratadas pelo que são: maneiras alternativas de promover o } \\
& \text { desenvolvimento intelectual dos jovens. Quanto mais nos focarmos em como um } \\
& \text { currículo reformado poderia resolver problemas sociais ou econômicos, menos } \\
& \text { provável é que esses problemas sociais e econômicos sejam tratados onde se } \\
& \text { originam, que não é na escola (Young, 2011: 399). }
\end{aligned}
$$

Logo, há falta de disposição das equipes diretivas das escolas em proporcionar espaços nos quais seja possível refletir sobre o papel da escola no enfrentamento da violência. Por sua vez, os professores, atolados de problemas de como gerir a sala de aula de forma a que possam possibilitar que os alunos aprendam, também não conseguem enfrentar a discussão sobre esses temas transversais que perpassam toda a vida escolar. Não se sentem preparados para discutir ou intervir na violência dentro da sala de aula, nem para discutir questões de gênero, sexualidade, diversidade. As discussões sobre a organização das escolas não podem, hoje, evitar os problemas relacionados com as categorias, as formas de subjetividade, o estatuto do saber e os mecanismos de poder (Varella, 1999).

Osalunos entrevistados também referiram piadas desrespeitosas, insinuações e comentários depreciativosem relação às diversidades de gênero, orientação sexual, raçaetnia, faixa etária, classe social, dentre outras. Esses silenciamentosnas instituições

Iluminuras, Porto Alegre, v. 19, n. 47, p. 210-226, dec, 2018. 
favorecerem com que os alunos reproduzam discursos machistas, heterossexistas, homofóbicos que apagam as diversidades.É preciso que a escola contribua para a construção de uma cultura contra violências, aprenda a lidar com as discriminações, intolerâncias e exclusão no espaço escolar, ainda que essas não se consubstanciem em violências físicas propriamente ditas (Abramovay, 2002).

Nesse sentido, o problema não é só aceitar ou tolerar as “diversidades”, mas, conforme Dinis e Cavalcanti (2008) afirmam, o desafio é criar políticas que questionem as normas que categorizam as identidades. Diante do exposto, Amaro (Amaro, 2012) reconhece que a escola que deveria proteger e defender os direitos humanos e sociais, abriga práticas, calcadas em atitudes racistas, sexistas e machistas, contrariando a função social que o Estado lhe atribui. A intolerância interfere no contexto escolar para que seja promovida uma educação cidadã, à diminuição das desigualdades, à efetiva consolidação dos direitos humanos como direito de todos (alunos, professores, corpo diretivo e famílias).

\section{CONSIDERAÇÕES FINAIS}

A partir da análise dos dados é perceptível que se torna crucial para o planejamento de ações conjuntas voltadas ao enfrentamento das múltiplas formas de violências, em especial, no contexto escolar. Nesse sentido, um dos desafios na contemporaneidade é a aproximação das famílias, dos demais setores da comunidade escolar e da sociedade no sentido de identificar as concepções do papel da escola e, se houver reducionismo ou crenças que limitam o trabalho em prol da diversidade, não fugir do embate.

Então, por meio da formação continuada, tanto os professores quanto a direção das escolas, podem se tornar mais capacitados para ponderar sobre todos os aspectos pedagógicos e sobre o currículo escolar e, para além deles, propor estratégias com a finalidade de sanar as dificuldades e instalar mudanças significativas no enfrentamento à violência no contexto escolar. Por meio da formação continuada, tanto os professores quanto o corpo diretivo das escolas tornam-se mais capacitados para ponderar sobre todos os aspectos pedagógicos e, para além deles, propor estratégias com a finalidade de sanar as dificuldades e instalar mudanças significativas no contexto escolar. A discussão sobre a 
violência deve estar em pauta constante no âmbito educacional, pois há a necessidade de fomentar pesquisas e planejar ações a fim de minimizá-la. A violência vivenciada na vida dos alunos e professores tem impacto importante nas relações e na permanência ou não desses sujeitos dentro da escola.

Neste estudo nos deparamos com o desafio para a prevenção à violência, à medida que o Ministério da Educação suprimiu do documento da Base Nacional Comum Curricular trechos, especificamente, que tratavam a respeito da diversidade sexual e gênero, atendendo a demandas de setores conservadores do governo e movimentos como a Escola sem Partido, este compromisso se tornou ainda mais desafiador. Assim, é fundamental que esses temas chamados transversais, como as questões de violência, possam ser abordadosno contexto escolar. Os resultados desta pesquisa poderão subsidiar o desenvolvimento de ações de prevenção no combate às violências e no cuidado com a saúde na escola para todos os implicados nesse processo (alunos, professores e corpo diretivo). Deste modo, essa discussão poderá auxiliar a visualizar coletivamente um conjunto de comportamentos, atitudes, expectativas, valores e estereótipos associados aos diferentes sujeitos que circulam nesse contexto escolar. Assim, essas informações poderão auxiliar propostas pedagógicas no delineamento de programas ou ações preventivas de acompanhamento ao trabalho dos professores e rever os currículos escolares para o debate desenvolvido no contexto escolar sobre o impacto das violências na saúde de todos os implicados.

\section{REFERÊNCIAS}

ABRAMOVAY, Miriam. Escola e violência / Miriam Abramovayet alii. - Brasília: UNESCO, 2002.

ABRAMOVAY, M.; RUA, M. das G. (coord.). Violências nas escolas. Brasília: UNESCO, 2002.

ABRAMOVAY, Miriam. Coord. Diagnóstico participativo das violências nas escolas: falam os jovens./ Miriam Abramovay, Mary Garcia Castro, Ana Paula da Silva, Luciano Cerqueira. Rio de Janeiro: FLACSO - Brasil, OEI, MEC, 2016.

AMARO, Sarita. Serviço Social na educação: bases para o trabalho profissional. Florianópolis: Ed. da UFSC, 2012. 
CACIANO, C e SILVA, GiulianaArboite.Foucault e educação: as práticas de poder e a escola atual. Vol.2 - Nº1 - AGO/2012 - ISSN2237-7077. 98.

DEBARBIEUX, Éric. La violenceenmillieuscolaire: ledésordredeschoses. Paris: ESF, 1999.

DEMO, Pedro. Participação é conquista: noções de política social participativa. São Paulo: Cortez, 1998,

DINIS, Nilson Fernandes. Discursos sobre homossexualidade e gênero na formação em pedagogia. Pro-posições, v. 19, n. 2, p. 99-109, 2008.

FABRIS, Eli. In/exclusão no currículo escolar: o que fazemos com os “incluídos”?

Educação. Unisinos. n.15. v. 1 p. 32-39, janeiro/abril 2011.

FOUCAULT, Michel. Em defesa da sociedade. Tradução de Maria Ermantina Galvão. São Paulo: Martins Fontes, 1999.

FOUCAULT, M. Vigiar e punir: história da violência nas prisões. Petrópolis: Vozes, 1987.

GARCIA, Maria Manuela Alves. O sujeito emancipado das pedagogias críticas. Educação \& Realidade, Porto Alegre, v. 26, n.2, p. 31-50, 2001.

GIL, Antônio Carlos. Como elaborar projetos de pesquisa. 4 ed. São Paulo, SP: Atlas, 2002.

LEOPARDI, M. T. et al. Metodologia da Pesquisa na Saúde. Santa Maria: Pallotti, 2001.

LOCKMANN, Kamila. O papel expansionista da escola contemporânea. Série Estudos. Periódico do programa de Pós-graduação em Educação da UCDB. Vol. 21, n. 43, set/dez, 2016.

LOURO, Guacira Lopes. Corpo, escola e identidade. Educação \& Realidade, v. 25, n. 2, 2000.

LOURO, Guacira Lopes. Gênero, sexualidade e educação: uma perspectiva pósestruturalista. São Paulo: Editora Vozes, 1999.

MINAYO; Maria Cecília de Souza. É possível prevenir a violência? Reflexões a partir do campo da saúde pública. Ciência e Saúde Coletiva, V.4, nº1, 1999. pg.10.

PAIN, Jacques. La violence institutionnelle ?Aller plus loin dans la question sociale. 2002. Disponível em: http:// probo.free.fr/textes_amis/violence_institutionnelle_j_pain.pdf

Iluminuras, Porto Alegre, v. 19, n. 47, p. 210-226, dec, 2018. 
Acessado em novembro, 2015.

SARAIVA, Karla; VARGAS, Juliana. Os perigos da Escola sem Partido. Teias, v.8, n.51, p.68- 54, out.-dez. 2017.

VARELA, Julia. Categorias espaço-temporais e socialização escolar: do individualismo ao narcisismo. In: COSTA, Marisa Vorraber (Org.). Escola básica na virada do século: cultura, política e currículo. São Paulo: Cortez, 1999. p. 73-106.

YOUNG, Michel. O futuro da educação em uma sociedade do conhecimento: a defesa radical de um currículo disciplinar. Cadernos de Educação, Pelotas, RS, n. 38, p. 395-416, jan./abr. 2011.

Recebido 09 de setembro 2018

Aprovado 15 de dezembro 2018 